\title{
16. STRONTIUM, MANGANESE, AND IRON CONTENTS, AND OXYGEN ISOTOPES IN THE CARBONATE FRACTIONS RECOVERED FROM HOLE 398C, LEG 47B
}

\author{
Maurice Renard and Gilbert Richebois, Université Pierre et Marie Curie, \\ Laboratoire de Géologie des Bassins Sédimentaires, Paris, France \\ and \\ René Létolle, Université Pierre et Marie Curie, Laboratoire de Géologie Dynamique, Paris, France
}

\section{INTRODUCTION}

The strontium, manganese, and iron concentrations of the carbonate fraction were measured in samples from Hauterivian to Pleistocene sedıments. The carbonate fraction was obtained by crushing the samples and then dissolving them in acetic acid. Trace element analysis was conducted by atomic absorption spectrometry using the method described by Renard and Blanc (1971, 1972). Mineralogically, the composition of the carbonate fraction always corresponded to low magnesian calcite. Exceptions were found in Aptian-Albian beds which contained no calcium carbonates in spite of a high weight loss when dissolved in acetic acid. For these samples, X-ray analysis showed the presence of quartz, opal, amorphous matter, and rhodocrosite. All data are summarized in Table 1 .

\section{RELATIONSHIPS TO INSOLUBLE RESIDUE}

In some samples, the percentage of insoluble matter remaining after treatment with acetic acid was large enough to suggest contamination by the insoluble elements.

For strontium, the concentrations measured generally show no correlation with the levels of insoluble matter (Figure 1). However, a more detailed analysis shows a distinct positive correlation for all Hauterivian to Eocene samples. Therefore, the results are unreliable where the amount of insoluble matter is greater than 70 per cent. For manganese and iron content, no correlation was found with respect to the level of insoluble matter.

\section{STRONTIUM AND OXYGEN ISOTOPES}

Strontium concentrations, which are quite high during the Pliocene, Miocene, and Oligocene (Figure 2), show a sharp decline in Eocene and older rocks. This decline continues gradually to the Hauterivian and is due to increasing diagenesis with depth (Renard et al., 1978). It appears that the strontium lost from the carbonates must be trapped readily by the argillaceous rocks since a positive correlation between the level of strontium and the percentage of insoluble matter is found only in Eocene and older rocks. It is difficult to pinpoint the exact cause for the strontium loss. Depth (hence temperature and pressure) may play a part. However, the graph comparing strontium levels at different depths (Figure 3) is irregular and the variations in the amount of subsidence may be a causative factor. The relationship to sedimentation rate (Figure 4) is also not obvious. The periods of extremely high sedimentation (Miocene-Pliocene and Barremian-Hauterivian) do not show particularly high losses of strontium.

The levels of strontium tend to increase during the Maestrichtian, a phenomenum shown quite clearly at Holes 390 and 390A of Leg 44 (Renard et al., 1978). One possible cause is the weakness of the diagenetic process during this time. It also could be simply that the original strontium levels were higher during this period.

A strong positive correlation is shown between the isotopic oxygen composition and strontium concentrations (Figure 5). Statistical analysis shows:

Correlation coefficient " $r$ " $=0.8235$

Student, Fisher test $t=7.0055$ (39 samples)

Equation for correlation:

$[\mathrm{SR}] \mathrm{ppm}=398-93\left[\delta^{18} \mathrm{O}\right]+1273-74$.

We suggest that this positive correlation (already seen in Leg 44) is characteristic of diagenesis, a finding which agrees with those of Veizer (1977).

From Figure 5, it can be seen that regardless of which fractions are considered (Strontium levels of oxygen isotopes), the geochemical (diagenetic) division is situated between the Eocene and the Oligocene epochs. At present, we can offer no causal explanation for this.

\section{MANGANESE}

The distribution graph for manganese concentrations (Figure 6) shows the following:

a) Two impoverished zones: (1) the Miocene and (2) the Hauterivian-Barremian;

b) One rich zone from the Maestrichtian to the early Oligocene (particularly the late Eocene).

The manganese level in a carbonate depends upon two principal factors. One factor is oxidation reduction conditions during deposition (Michard, 1969). In a reducing medium, the manganese coprecipitates with the carbonate which leads to manganese-poor limestones. In an oxidizing medium, manganese dioxide precipitates, leading to limestones rich in this element. 
TABLE 1

Data Summary of Carbonate Fractions Analyses, Hole 398C

\begin{tabular}{|c|c|c|c|c|c|c|c|c|}
\hline $\begin{array}{c}\text { Sample } \\
\text { (Interval in } \mathrm{cm} \text { ) }\end{array}$ & $\begin{array}{l}\text { Carbonate } \\
\text { Mineralogy }\end{array}$ & $\begin{array}{l}\text { Solubility in } \\
\text { Acetic Acid }\end{array}$ & $\begin{array}{c}\mathrm{Mn} \\
(\mathrm{ppm})\end{array}$ & $\begin{array}{c}\mathrm{Sr} \\
(\mathrm{ppm})\end{array}$ & $\begin{array}{c}\mathrm{Fe} \\
(\mathrm{ppm})\end{array}$ & $\begin{array}{l}\delta^{18} \mathrm{O} \\
(\%)\end{array}$ & $\begin{array}{l}\delta^{13} \mathrm{C} \\
(\%)\end{array}$ & Age \\
\hline $2-2,60-67$ & Calcite & 71.05 & 314 & 1710 & 508 & 0.73 & -0.10 & Pliocene \\
\hline $3-2,70$ & Calcite & 76.07 & 404 & 1630 & 563 & 0.84 & 0.80 & Miocene \\
\hline $4-2,60-62$ & Calcite & 88.67 & 288 & 1897 & 314 & 0.94 & 0.96 & Miocene \\
\hline $5-2,40-42$ & Calcite & 89.84 & 243 & 1858 & 176 & 1.35 & 1.53 & Miocene \\
\hline $5-2,60-62$ & Calcite & 90.24 & 193 & 1820 & 177 & 1.08 & 1.63 & Miocene \\
\hline $5-4,44-46$ & Calcite & 90.82 & 266 & 1621 & 196 & 1.44 & 1.60 & Miocene \\
\hline $6-3,40-42$ & Calcite & 67.30 & 323 & 1935 & 269 & 1.32 & 2.40 & Miocene \\
\hline $6-3,60-62$ & Calcite & 82.28 & 367 & 1747 & 222 & 1.52 & 2.60 & Miocene \\
\hline $6-4,31-33$ & Calcite & 87.25 & 458 & 1781 & 275 & 1.68 & 2.65 & Miocene \\
\hline $7-2,58-60$ & Calcite & 78.32 & 583 & 1433 & 304 & 1.03 & 1.54 & Miocene \\
\hline $9-3,99-101$ & Calcite & 89.86 & 575 & 1539 & 321 & 1.42 & 1.73 & Miocene \\
\hline $13-3,62-64$ & Calcite & 58.63 & 1620 & 1736 & 109 & 1.11 & 1.54 & Oligocene \\
\hline $14-1,35-37$ & Calcite & 70.05 & 1094 & 1625 & 152 & 1.54 & 1.53 & Oligocene \\
\hline $15-2,45-46$ & Calcite & 72.64 & 938 & 1695 & 112 & 1.30 & 1.37 & Oligocene \\
\hline $20-3,118-120$ & Calcite & 20.96 & 5469 & 1952 & 274 & -0.94 & 2.15 & Eocene \\
\hline $21-2,77-79$ & No calcium carbonate & 7.23 & 6405 & 733 & 1332 & -0.03 & +1.66 & Eocene \\
\hline $22-3,23-25$ & Calcite & 35.67 & 3700 & 1085 & 72 & -0.03 & +1.66 & Eocene \\
\hline $23-2,41-45$ & Calcite & 16.79 & 3254 & 906 & 424 & -0.62 & +1.72 & Eocene \\
\hline $25-1,102-104$ & Calcite & 16.29 & 6523 & 1462 & 258 & -0.33 & +1.61 & Eocene \\
\hline $26-2,39-41$ & Calcite & 33.72 & 4008 & 1302 & 80 & -0.02 & +1.67 & Eocene \\
\hline $27-4,89-91$ & Calcite & 35.57 & 2723 & 1483 & 166 & -1.27 & +1.55 & Eocene \\
\hline $28-2,54-56$ & Calcite & 27.97 & 1241 & 1450 & 209 & -0.80 & +1.75 & Eocene \\
\hline $30-4,132-134$ & Calcite & 32.96 & 1943 & 1457 & 158 & -1.12 & +1.74 & Eocene \\
\hline $32-1,95-97$ & Calcite & 19.40 & 2078 & 1112 & 253 & & & Eocene \\
\hline $33-2,141-142$ & Calcite & 51.20 & 1855 & 841 & 67 & -0.93 & +0.71 & Eocene \\
\hline $35-2,77-79$ & Calcite & 61.17 & 2532 & 1028 & 64 & -0.75 & +1.44 & Eocene \\
\hline $36-2,100-102$ & Calcite & 41.93 & 3574 & 1139 & 89 & -0.85 & +2.55 & Paleocene \\
\hline $38-2,56-58$ & Calcite & 39.29 & 3360 & 1102 & 29 & -0.45 & +2.15 & Paleocene \\
\hline $39-2,43-45$ & Calcite & 37.15 & 3313 & 1140 & 55 & -0.11 & +1.63 & Paleocene \\
\hline $40-1,9-11$ & Calcite & 41.05 & 3477 & 934 & 79 & & & Paleocene \\
\hline $41-2,8-10$ & Calcite & 55.35 & 1529 & 1202 & 71 & -0.25 & +1.38 & Paleocene \\
\hline $41-2,31-33$ & Calcite & 41.46 & 2336 & 1011 & 112 & -0.26 & +0.90 & Paleocene \\
\hline $41-2,38-40$ & Calcite & 9.46 & 3000 & 1229 & 491 & -1.08 & +1.61 & Paleocene \\
\hline $41-2,45-47$ & Calcite & 55.23 & 1813 & 803 & 42 & -0.27 & +2.19 & Paleocene \\
\hline $41-2,65-68$ & Calcite & 59.97 & 2285 & 847 & 36 & -0.37 & +2.24 & Paleocene \\
\hline $41-2,131-133$ & Calcite & 55.55 & 2316 & 749 & 39 & -0.12 & +2.38 & Paleocene \\
\hline $42-2,93-95$ & Calcite & 48.26 & 2460 & 976 & 74 & & & Maestrichtian \\
\hline $43-2,16-18$ & Calcite & 57.96 & 2028 & 1169 & 57 & -0.48 & +2.53 & Maestrichtian \\
\hline $44-2,65-67$ & Calcite & 63.35 & 1565 & 1060 & 41 & & & Maestrichtian \\
\hline $45-1,18-20$ & Calcite & 38.29 & 2803 & 1111 & 103 & -0.59 & +2.02 & Maestrichtian \\
\hline $46-2,28-30$ & Calcite & 43.63 & 4214 & 1047 & 106 & -0.43 & +1.69 & Maestrichtian \\
\hline $47-1,45-47$ & Calcite & 24.56 & 3677 & 805 & 96 & & & Maestrichtian \\
\hline $56-3,12-14$ & No calcium carbonate & 7.46 & 819 & Néant & 6920 & & & Cenomanian \\
\hline $57-2,101-103$ & Calcite & 55.65 & 4958 & 863 & 439 & & & Cenomanian \\
\hline $93-1,86-87$ & No calcium carbonate & 37.46 & 210.900 & 95 & $>50.000$ & & & Albian \\
\hline $111-3,72-74$ & No calcium carbonate & 33.37 & 195.000 & 125 & 29.940 & & & Aptian \\
\hline $116-3,80-82$ & No calcium carbonate & 69.22 & 265.400 & 149 & 14.975 & & & Aptian \\
\hline $130-4,78-80$ & Calcite & 23.55 & 622 & 1099 & 1938 & & & Barremian \\
\hline $132-2,108-109$ & Calcite & 31.88 & 1108 & 416 & 6191 & & & Barremian \\
\hline $133-2,51-53$ & Calcite & 54.38 & 1313 & 682 & 1876 & -1.77 & +1.31 & Barremian \\
\hline $134-2,78-80$ & Calcite & 40.67 & 1450 & 771 & 1695 & -1.47 & +1.50 & Hauterivian \\
\hline $135-2,27-29$ & Calcite & 44.70 & 864 & 662 & 1788 & -1.74 & +1.09 & Hauterivian \\
\hline $137-2,24-26$ & Calcite & 75.41 & 960 & 486 & 2674 & -1.50 & +1.12 & Hauterivian \\
\hline $138-1,38-40$ & Calcite & 87.10 & 1241 & 395 & 3843 & -1.57 & +1.08 & Hauterivian \\
\hline
\end{tabular}

Secondly, the manganese level in a carbonate is influenced by the amount of manganese in the seawater, which introduces the problem of its origin. The manganese can be the result of either continental erosion or submarine volcanoes (an exhaustive bibliography dealing with this subject is in Cronan, 1974).
Regarding Site 398, we believe that the high levels of manganese are due to submarine volcanic activity (hydrothermal and/or magmatic emanations). From the Maestrichtian to the early Oliogocene, there was a period of volcanic activity, reaching maximum intensity in the late Eocene. 

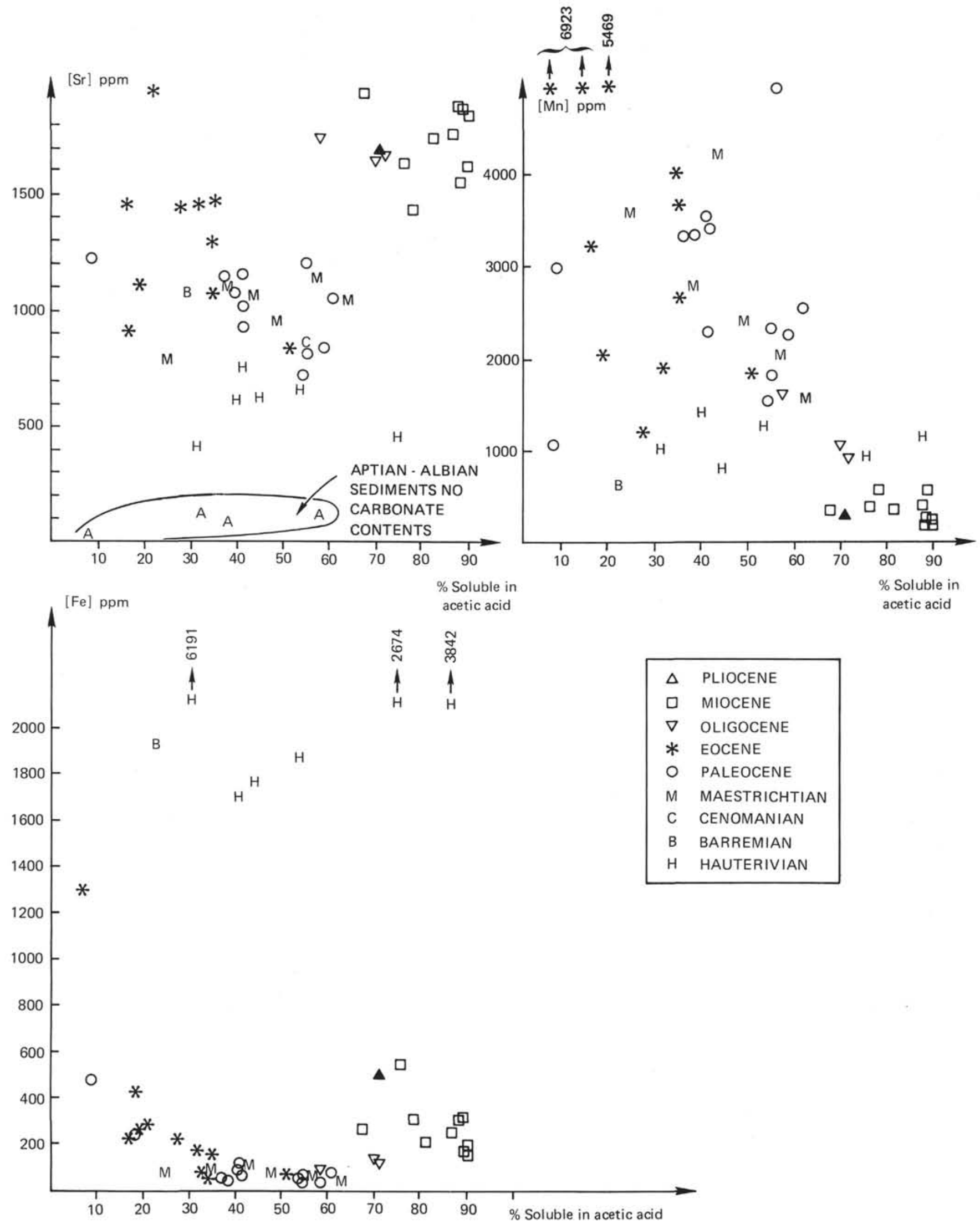

Figure 1. Relationship between trace element concentrations and insoluble residue percentage after acetic acid dissolution. 


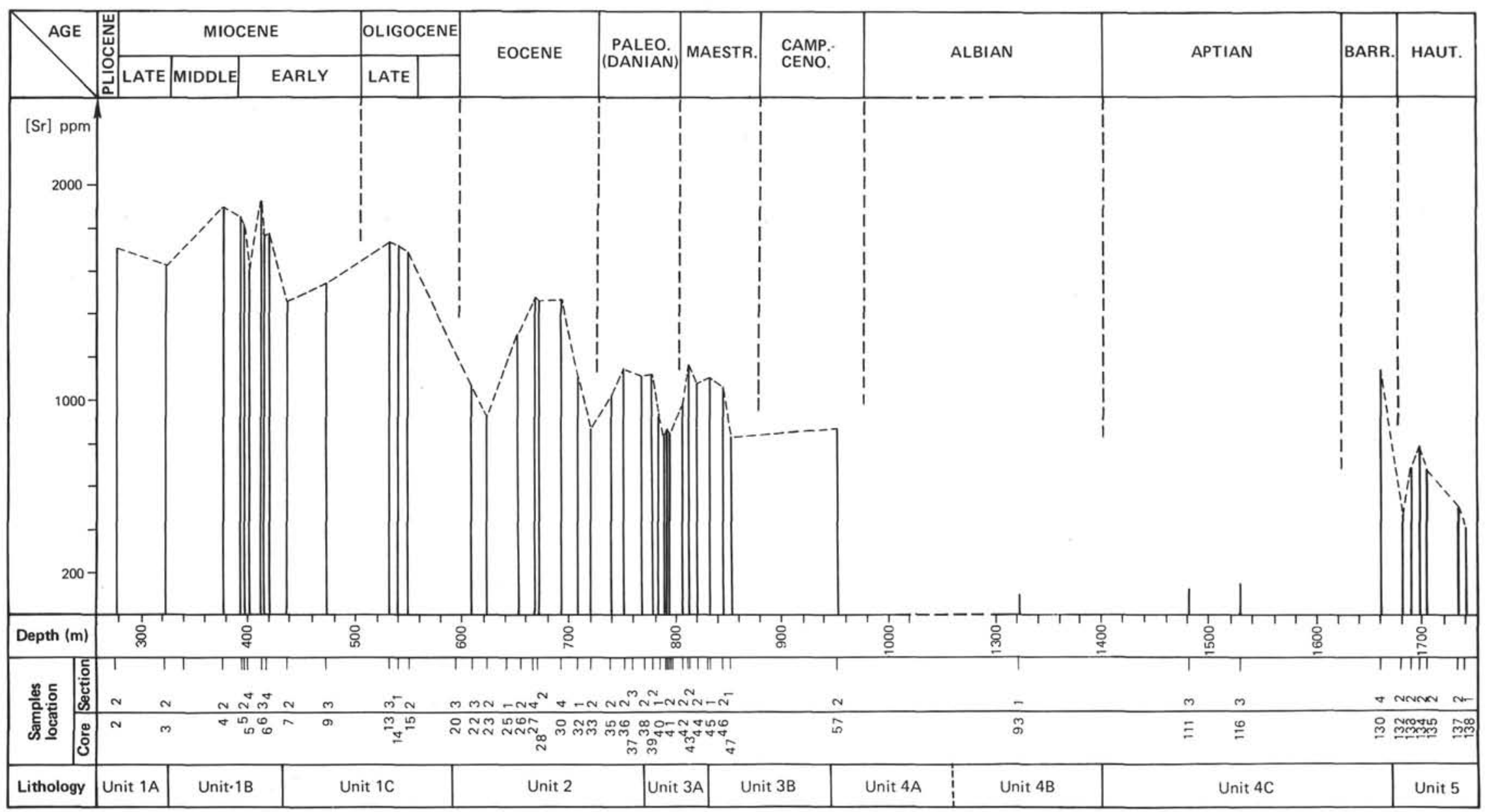

Figure 2. Distribution curve for strontium concentrations. 


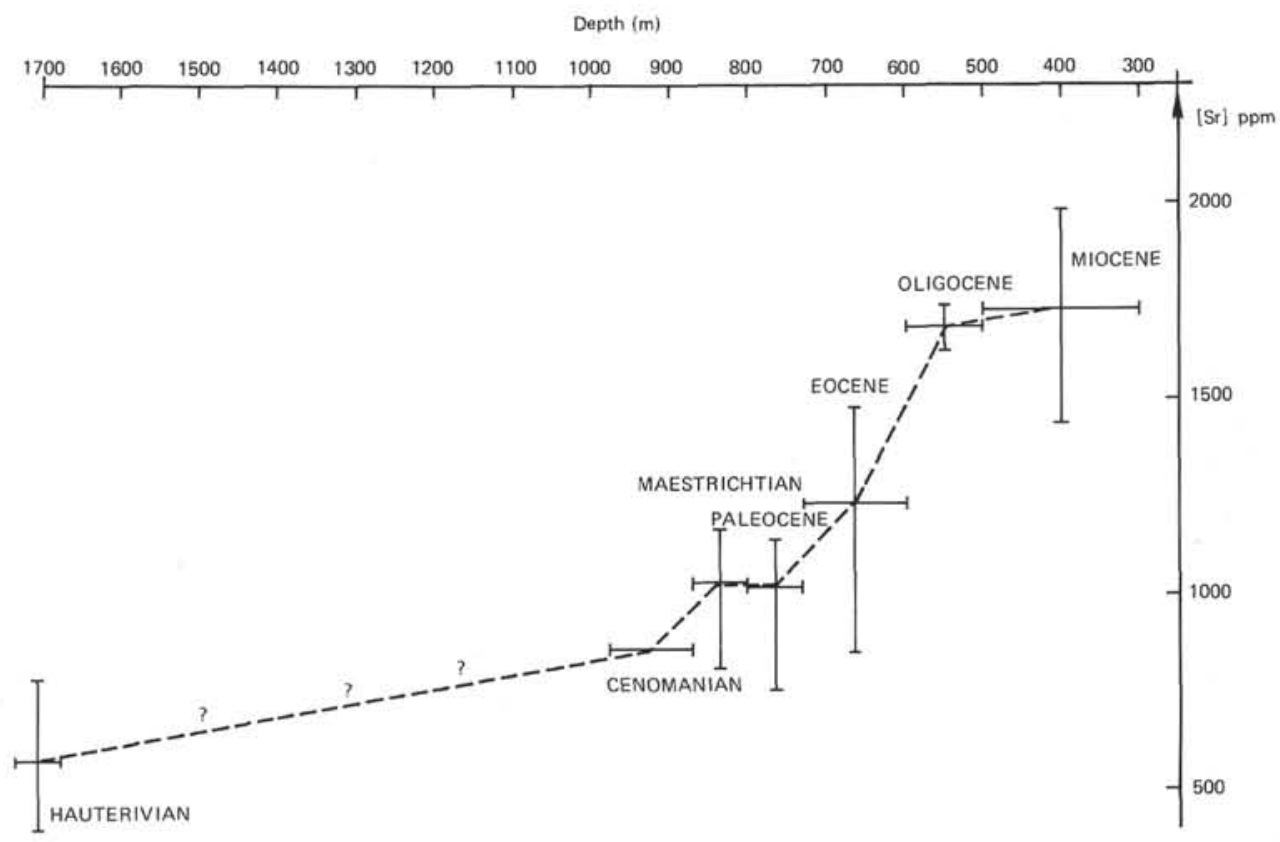

Figure 3. Strontium concentration as a function of depth in the hole.

\section{IRON}

The distribution of iron (Figure 7) can be divided into three basic periods.

1) A high concentration zone in Barremian and Hauterivian time;

2) A low concentration zone in the Miocene-Pliocene;

3) A very low concentration zone between the Maestrichtian and the Oligocene.

As was true for manganese, the problem is to determine the origin of these varying concentrations; once again, there can be either continental erosion or submarine volcanic activity.

For the Barremian to Hauterivian and the MiocenePliocene periods, we think that the iron originated from continental erosion. Given that the solubility products of iron and manganese oxides are very different, it normally would not be possible for the two elements to be co-precipitated. Figure 8 shows that those samples with a high concentration of iron have a correspondingly low concentration of manganese and vice versa. It becomes possible, therefore, to outline the basic characteristics of particular groups of samples, as we already have done for Leg 44 (Renard et al., 1978).

A group of samples from Site 398 with a high concentration of iron is characteristic of continental erosion sediments (Hauterivian, Barremian, and Miocene-Pliocene). Similarly, a group of samples with a high concentration of manganese is characteristic of volcanic sediments (Maestrichtian to Oligocene). The high concentrations of iron in the Hauterivian and Barremian samples imply a close proximity to the coastline.

There remains the problem of the Aptian-Albian samples. These were found to be totally lacking in calcium carbonates; however, they did contain high concentrations of both manganese $(200,000 \mathrm{ppm})$ and iron compounds ( 20,000 to $40,000 \mathrm{ppm})$, when treated with acetic acid. The fact that these concentrations are always associated with the formation of new ocean floor leads us to postulate that the Aptian-Albian period was one of important oceanic expansion for this particular region, a finding which seems to agree with the geophysical data.

\section{ACKNOWLEDGMENTS}

We are grateful to Michel Petzoid for preparation of the figures and to Annette Gréaud for typing various drafts of the manuscript. Centre National de la Recherche Scientifique provided financial support through Action Thèmatique Programmée "IPOD."

\section{REFERENCES}

Cronan, D. S., 1974. Authigenic minerals in deep sea sediments. In The sea: New York (Wiley and Sons), v. 5, p. 491-525.

Michard, G., 1969. Contribution à l'étude du comportement du Manganèse dans la sédimentation, Thesis, University of Paris.

Renard, M. and Blanc, P., 1971. Mise au point d'un protocole expérimental pour le dosage d'éléments en traces (V, $\mathrm{Cr}, \mathrm{Mn}, \mathrm{Ni}, \mathrm{Sr}, \mathrm{Mo}$ ) par absorption atomique, C. R. Acad. Sci., v. 272 , p. $2285-2288$.

1972. Influence des conditions de mise en solution (choix de l'acide, température et durée d'attaque) dans le dosage des éléments en traces des roches carbonatées, C. R. Acad. Sci., v. 274, p. 632-635.

Renard, M., Létolle, R., and Bourbon, M., 1978. Some trace elements in the carbonate samples recovered from Holes 390, 390 A, 391C, and 392A of Leg 44. In Benson, W. E., Sheridan, R. E., et al., Initial Reports of the Deep Sea Drilling Project, v. 44: Washington (U.S. Government Printing Office), p. 557-566.

Veizer, J., 1977. Diagenesis of pre-Quaternary carbonates as indicated by tracer studies, J. Sediment. Petrol., v. 47, p. 565-579. 


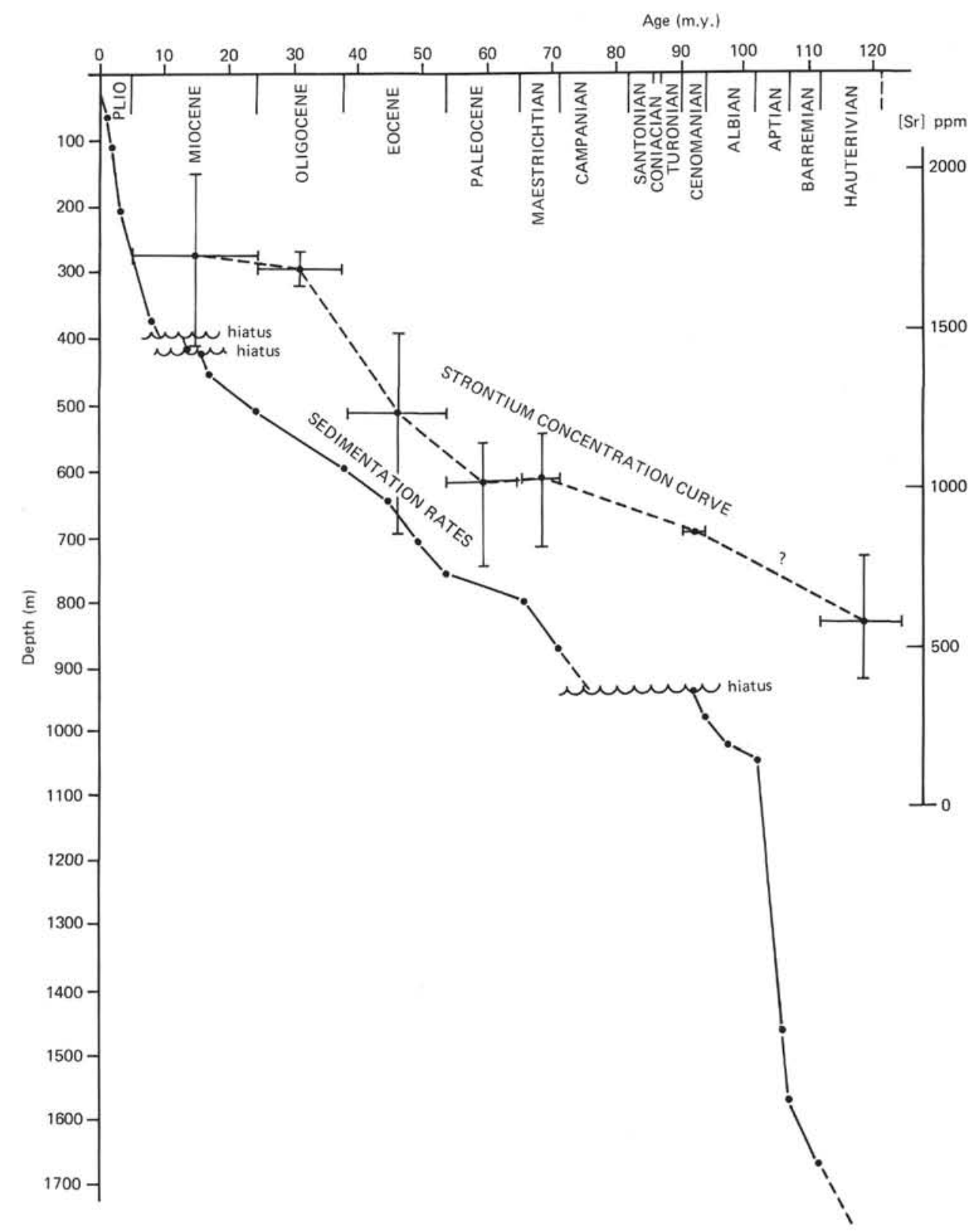

Figure 4. Relationship between the sedimentation rates curve and the distribution curve of strontium concentrations. 


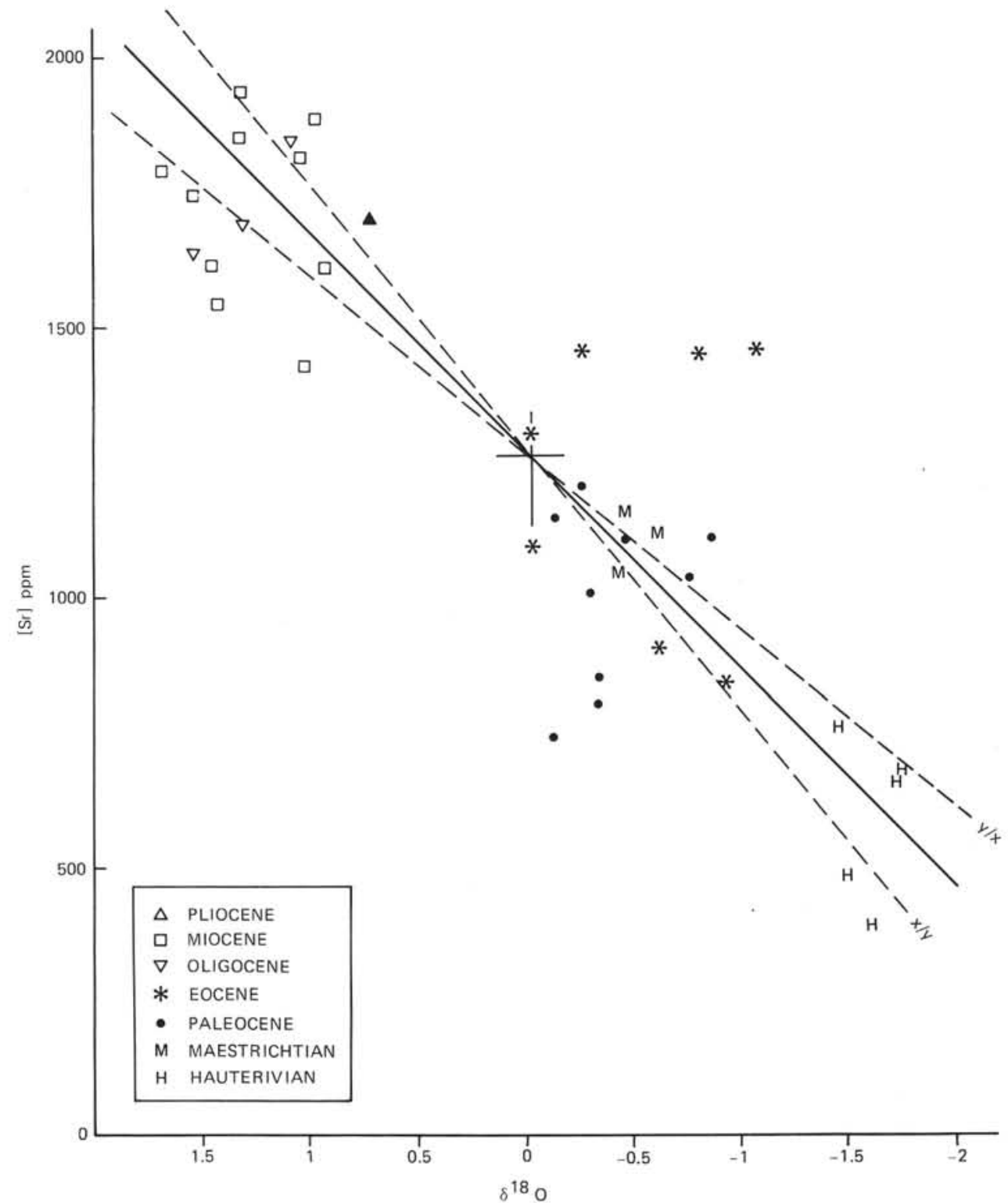

Figure 5. Relationship between isotopic oxygen composition and strontium concentrations. 


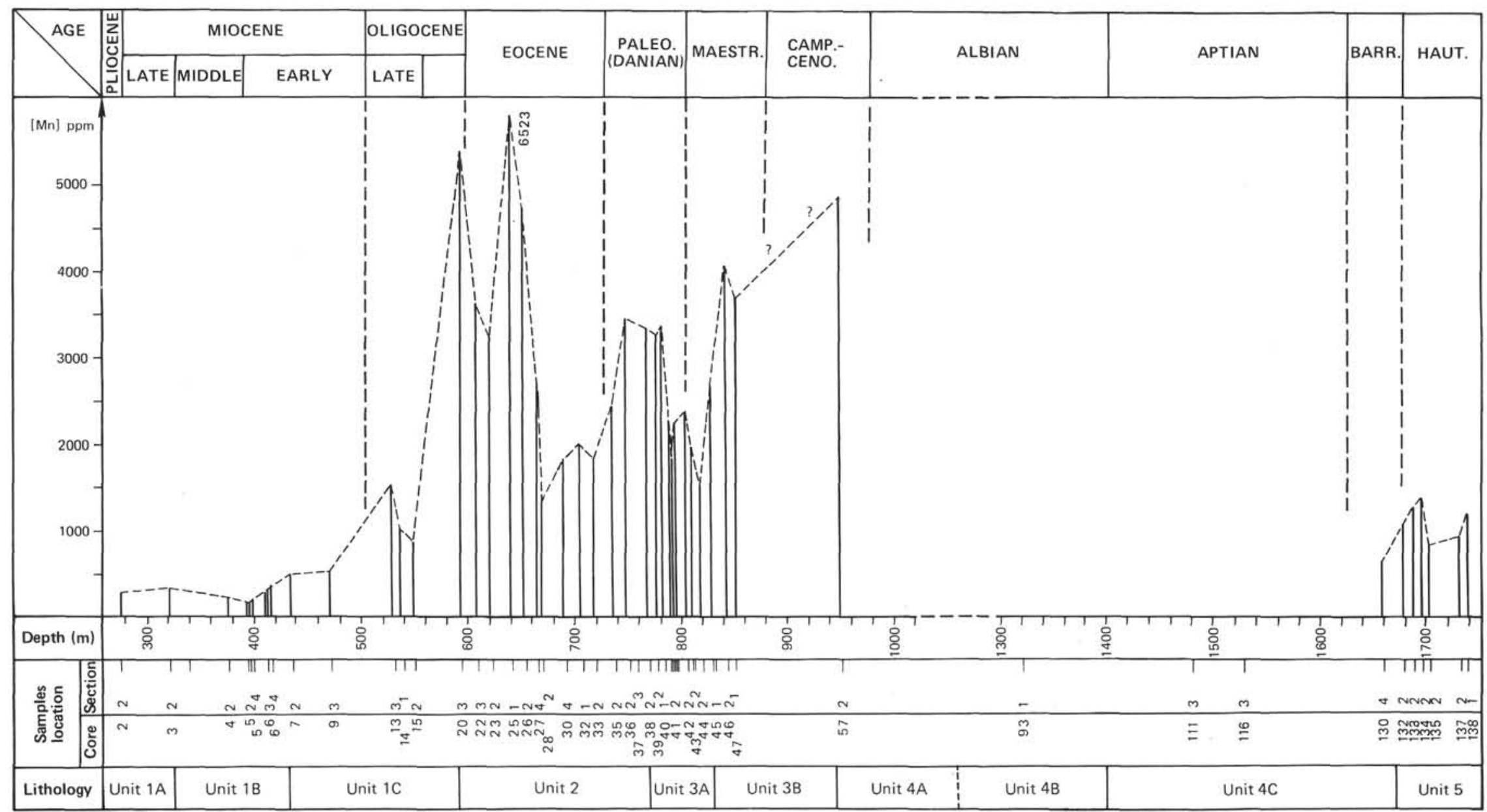

Figure 6. Distribution curve for manganese concentrations. 


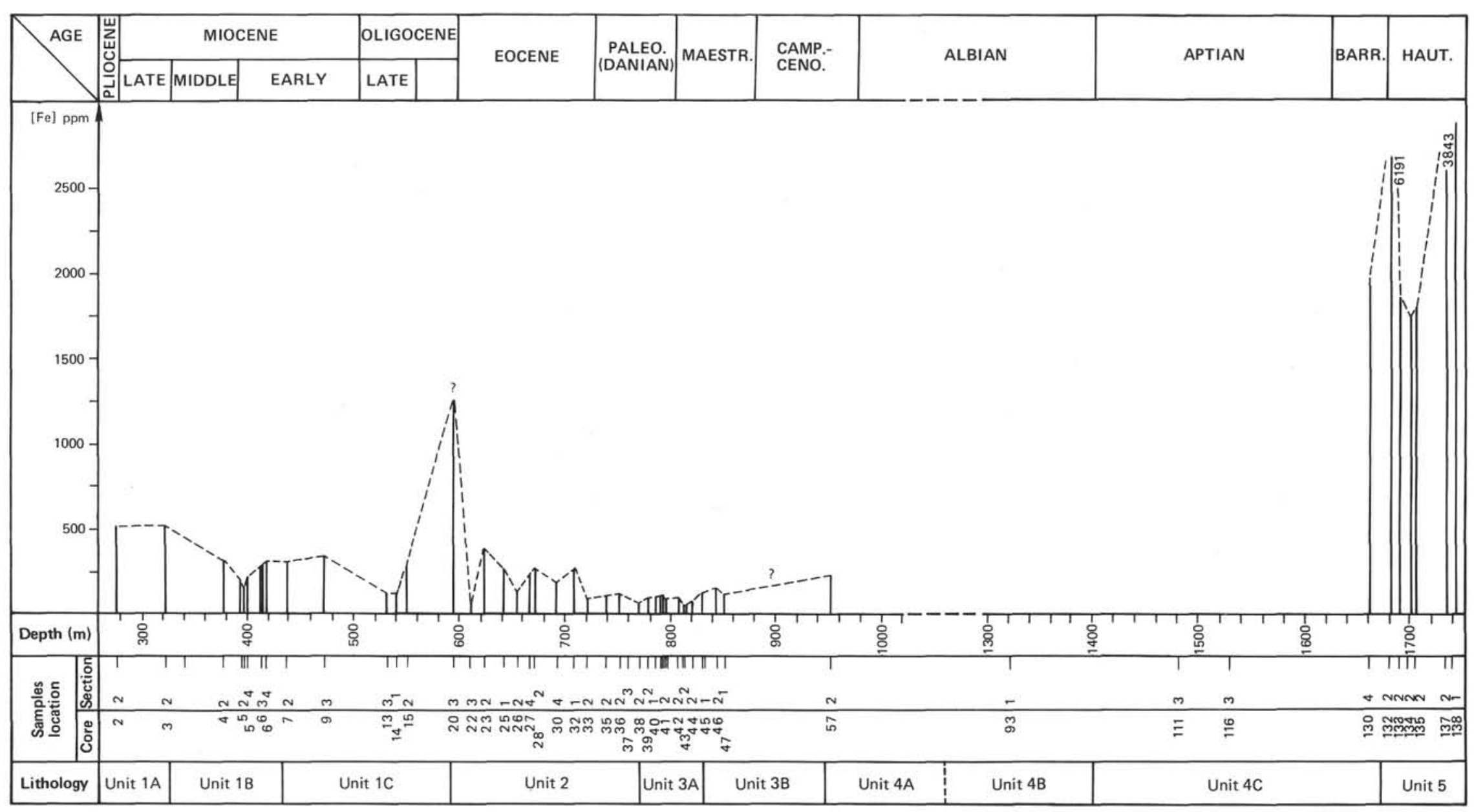

Figure 7. Distribution curve for iron concentrations. 


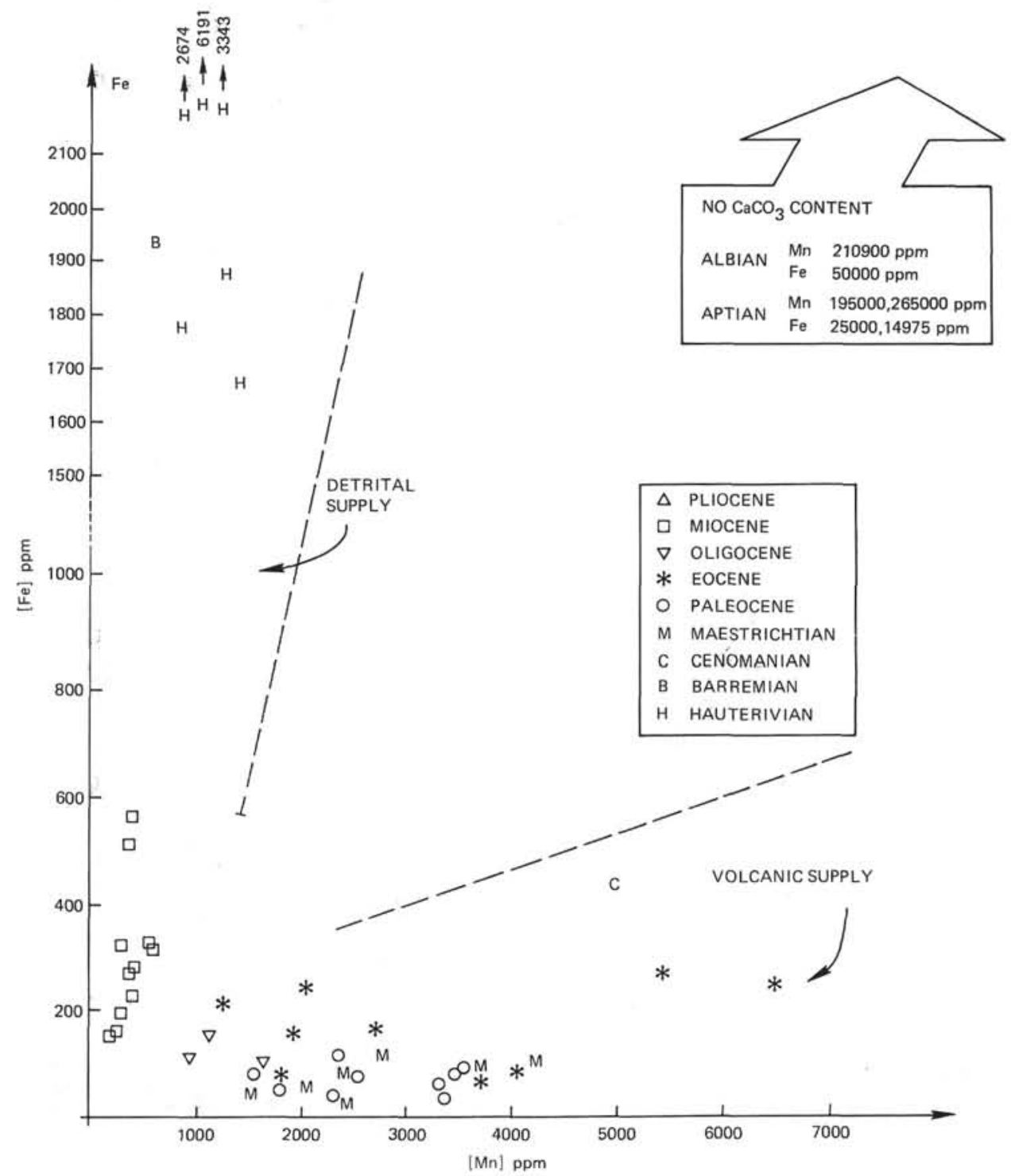

Figure 8. Relationship between iron and manganese concentrations. 